\title{
Controlled Geometry Formation of the Carbon Coils by the Substrate Pretreatment
}

\author{
Semi Park and Sung-Hoon Kim \\ Department of Engineering in Energy \& Applied Chemistry, Silla University, Busan 617-736, Republic of Korea \\ Correspondence should be addressed to Sung-Hoon Kim; shkim@silla.ac.kr
}

Received 12 July 2013; Accepted 12 August 2013

Academic Editors: B. A. Marinkovic and A. Ohtaka

Copyright (C) 2013 S. Park and S.-H. Kim. This is an open access article distributed under the Creative Commons Attribution License, which permits unrestricted use, distribution, and reproduction in any medium, provided the original work is properly cited.

Carbon coils could be synthesized using $\mathrm{C}_{2} \mathrm{H}_{2} / \mathrm{H}_{2}$ as source gases and $\mathrm{SF}_{6}$ as an incorporated additive gas under thermal chemical vapor deposition system. Prior to the carbon coils deposition reaction, the supporting substrates were pretreated using various methods. Among the methods, the thermal etching pretreatment of $\mathrm{Ni}-\mathrm{SiO}_{2}$ substrate with $\mathrm{SF}_{6}$ leads to the exclusive formation of the nanosized carbon coils. The diamond powders pretreatment of Si substrate gives rise to the dominant formation of the microsized carbon coils after 10 minutes reaction time. The geometry selectivity for the carbon coils in a specific pretreatment method was discussed in association with the peeled-off Ni layers by the thermal etching pretreatment with $\mathrm{SF}_{6}$ and the remained carbon particles on Si substrate by the diamond powders pretreatment.

\section{Introduction}

Although the unique geometries of the carbon coils have been attracted as the promising potential materials in nano/microelectronics or mechanics [1-4], the controlled geometry for as-grown carbon coils should be preferentially solved to practically apply them in diverse application fields $[5,6]$.

The metal catalyst was regarded as one of the indispensable factors for the formation of the carbon coils [711]. In addition, the characteristics of the used metal catalyst seem to affect the formation density and the geometry of the carbon coils via the vapor-liquid-solid growth mechanism of the carbon nanomaterials [9-13]. Meanwhile, the property of the supporting substrate may alternate the characteristics of the used metal catalyst, consequently affecting the formation density and the geometries of the as-grown carbon coils $[13,14]$. Until now, Huang et al. reported that the formation of the carbon nanocoils would be critically affected by the morphology change of $\mathrm{Si}$ substrate which was induced by the HF solution corrosion [15]. They found the coils formation exclusively on the concavo-convex surface morphology of $\mathrm{Si}$ substrate with the straight carbon nanotubes on the flat Si surface, namely, on noncorroded Si surface. Veziri et al. demonstrated that the morphology of the carbon nanostructures grown by chemical vapor deposition (CVD) on the porous supports is strongly affected by the porosity of the supporting substrate [16]. Bai obtained a more or less controlled morphology of the carbon coils through the careful choice of alumina substrate pore size [17]. Despite many efforts to enhance the controlled geometry for the carbon coils, detailed reports regarding the effect of the substrate pretreatment on the formation of the carbon coils are still required.

This work introduces the geometry selectivity for the as-grown carbon coils by the pretreatment of the substrate surface. Prior to the carbon coils deposition reaction, the pretreatment of the supporting substrates ( $\mathrm{Si}$ and $\mathrm{SiO}_{2}$ substrates) was carried out using diamond powders, $\mathrm{SiC}$ sandpaper, and thermal etching with $\mathrm{SF}_{6}$. To elucidate the exact cause for the exclusive growth of the carbon coils having the controlled geometry, systematic investigations for the substrate pretreatment effect were carried out and discussed.

\section{Experimental Details}

For silicon substrate, p-type $\mathrm{Si}(100)$ substrates were used. For its oxide substrate, $\mathrm{SiO}_{2}$ layered $\mathrm{Si}$ substrates were employed. $\mathrm{SiO}_{2}$ layered $\mathrm{Si}$ substrates in this work were prepared by the 
thermal oxidation of $2.0 \times 2.0 \mathrm{~cm}^{2}$ p-type $\mathrm{Si}(100)$ substrates. The thickness of silicon oxide $\left(\mathrm{SiO}_{2}\right)$ layer on $\mathrm{Si}$ substrate was estimated to be about $300 \mathrm{~nm}$.

Four kinds of the pretreatment methods were performed as follows.

(a) Method-A, the substrates were pretreated by the diamond powders: the diamond powders pretreatment was carried out by an ultrasonic treatment for 60 minutes using about $0.5 \mathrm{~g}$ diamond powders in an acetone solution. Various micrometer sizes of synthetic diamond particles were used as diamond powders.

(b) Method-B, the substrates were pretreated by $\mathrm{SiC}$ sand paper: unidirectional scratching using $\mathrm{SiC}$ sand paper was carried out for several times. The grain size of $\mathrm{SiC}$ was around $70 \mu \mathrm{m}$ in diameter.

(c) Method-C, the substrates were pretreated by thermal etching with $\mathrm{SF}_{6}$ : in this case, the substrates were heated up to $750^{\circ} \mathrm{C}$ in the thermal CVD reactor. And then, pure $\mathrm{H}_{2}$ flow $(35 \mathrm{sccm})+\mathrm{SF}_{6}$ flow $(35 \mathrm{sccm})$ were injected into the reactor up to 100 torr total pressure. After 5 minutes, the heater and $\mathrm{H}_{2}+\mathrm{SF}_{6}$ flow injection were turned off, and then the reactor cooled down in a vacuum state $\left(10^{-2}\right.$ torr).

(d) Method-D, the substrates were first deposited by $\mathrm{Ni}$ thin catalyst layer (about $200 \mathrm{~nm}$ thickness), and then they were pretreated by Method-C.

After the pretreatment of the substrate, Ni catalyst layer deposition on the substrates was carried out. For Ni catalyst layer deposition on the substrates, a $0.1 \mathrm{~g}$ Ni powder $(99.7 \%)$ was evaporated for 1 minute to form the $\mathrm{Ni}$ catalyst layer on the substrate using thermal evaporator. The estimated $\mathrm{Ni}$ catalyst layer on the substrate was about $200 \mathrm{~nm}$.

The carbon coils deposition was performed on the $\mathrm{Ni}$ catalyst layer deposited substrates using thermal CVD system. $\mathrm{C}_{2} \mathrm{H}_{2}$ and $\mathrm{H}_{2}$ were used as source gases. $\mathrm{SF}_{6}$, as an incorporated additive gas, was injected into the reactor for 5 minutes during the initial deposition time. The flow rate for $\mathrm{C}_{2} \mathrm{H}_{2}, \mathrm{H}_{2}$, and $\mathrm{SF}_{6}$ was fixed at 15,35 , and $35 \mathrm{sccm}$, respectively. Two kinds of the overall deposition time for asgrown carbon coils were applied in this work. Namely, one is $\mathrm{H}_{2}+\mathrm{C}_{2} \mathrm{H}_{2}+\mathrm{SF}_{6}$ flow for 5 minutes during the initial deposition time and the consecutive $\mathrm{H}_{2}+\mathrm{C}_{2} \mathrm{H}_{2}$ flow for 5 minutes, and another is $\mathrm{H}_{2}+\mathrm{C}_{2} \mathrm{H}_{2}+\mathrm{SF}_{6}$ flow for $5 \mathrm{~min}$ during the initial deposition time and the consecutive $\mathrm{H}_{2}+$ $\mathrm{C}_{2} \mathrm{H}_{2}$ flow for 55 minutes. The reaction conditions with the various substrates and the pretreatment methods were shown in Table 1.

The morphologies of the carbon coils-deposited substrates were investigated using field emission scanning electron microscopy (FESEM). Compositional analysis was performed by X-ray photoelectron spectroscopy (XPS).

\section{Results and Discussion}

Ten samples (samples $\mathrm{A} \sim \mathrm{J}$ ) having the different substrates and the pretreatment methods were prepared as shown in
Table 1. Substrates $\mathrm{A} \sim \mathrm{J}$ were placed in the substrate holder $\left(\mathrm{Al}_{2} \mathrm{O}_{3}\right.$ boat), and the syntheses of the carbon coils were simultaneously carried out on substrates $\mathrm{A} \sim \mathrm{J}$. Indeed, the different supporting substrates ( $\mathrm{Si}$ and $\mathrm{SiO}_{2}$ substrates) having the different pretreatment methods were simultaneously mounted on the substrate holder in the reaction chamber. So, the carbon coils formation reaction on the different supporting substrates with the different pretreatment methods would have an identical experimental condition.

Figures 1(a) and 2(a) show the prepared substrates by the various pretreatment methods. Figures 1(b) and 2(b) show the as-grown carbon coils on these substrates after $10 \mathrm{~min}$ utes (Figure 1(b)) and 60 minutes (Figure 2(b)) deposition reactions. As a naked eye, a lot of carbon materials seemed to be formed on the samples. For the nontreated substrate case, we could observe the formation of a lot of delaminated carbon-related materials on the samples surfaces, irrespective of the deposition times (see samples D and I in Figures 1(b) and 2(b)). On the other hand, the pretreatment of the substrate seems to reduce the delaminated phenomena (compare samples D and I with the others in Figures 1(b) and 2(b)).

Microscopic images for the as-grown carbon materials were also investigated using FESEM. Figure 3 shows FESEM images revealing the formation of the as-grown carbon coils on the various substrates after 10 minutes deposition time. Figure 4 shows the magnified FESEM images for Figure 3. For the thermal etching with $\mathrm{SF}_{6}$ on $\mathrm{Ni}-\mathrm{SiO}_{2}$ substrate, noticeably, the nanosized carbon coils were exclusively formed on $\mathrm{SiO}_{2}$ substrate as shown in Figures 3(e) and 4(e). For the diamond powders-pretreated substrate, meanwhile, the microsized carbon coils having a few micrometer-sized coil diameters were mostly observed on Si substrate as shown in Figures 3(f) and 4(f). Except samples E and F, both the nanosized carbon coils and the microsized ones were simultaneously observed on the samples. This result reveals that the selective formation of the carbon coils having specific geometry could be possible merely by the pretreatment of the different substrates, namely, the diamond powders pretreatment of Si substrate (MethodA) for the microsized carbon coils and the thermal etching pretreatment of $\mathrm{Ni}-\mathrm{SiO}_{2}$ substrate with $\mathrm{SF}_{6}$ (Method-C) for the nanosized carbon coils.

To investigate the detailed geometry for the as-grown carbon coils, the high-magnified FESEM image for samples $\mathrm{E}$ and $\mathrm{F}$ was also carried out. For sample E, the occurrence of the square-type shapes on the substrate in Figure 5(a) seems to be due to the thermal etching with $\mathrm{SF}_{6}$ during the reaction. Most of the nanosized carbon coils in sample E have wavelike nanosized coil type geometry [18] with a diameter of less than $0.3 \mu \mathrm{m}$. They seem to form a matrix of the wavelike nanosized coils (see Figures 5(b) and 5(c)). For sample F, the formation of the microsized carbon coils having almost the constant coil pitch of $\sim 0.2 \mu \mathrm{m}$ without any coil gap could be observed as shown in Figures 5(d) 5(f). The diameters of these coils are around $2.0 \mu \mathrm{m}$, and the lengths of these coils were estimated to be several tens of micrometers. The carbon nanofilaments that built up the microsized carbon coil have a circular type shape with a diameter of $\sim 0.5 \mu \mathrm{m}$. These carbon nanofilaments seem to be composed by two kinds 


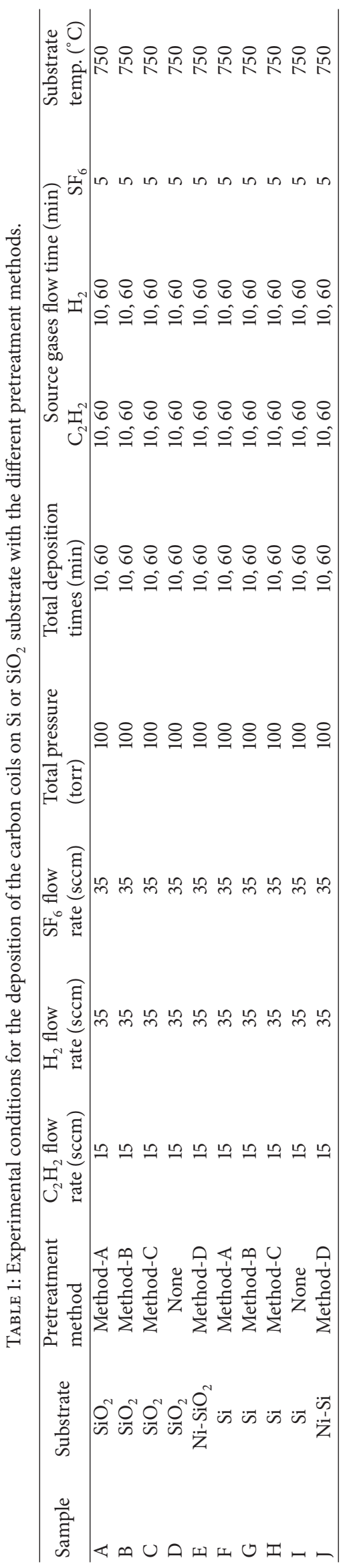




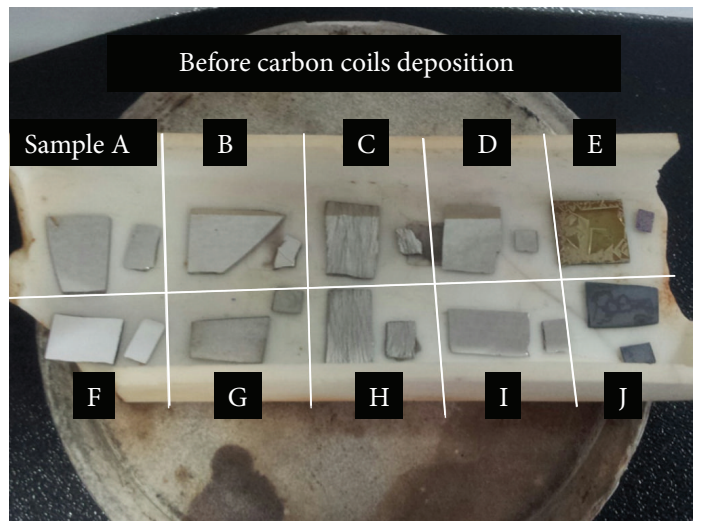

(a)

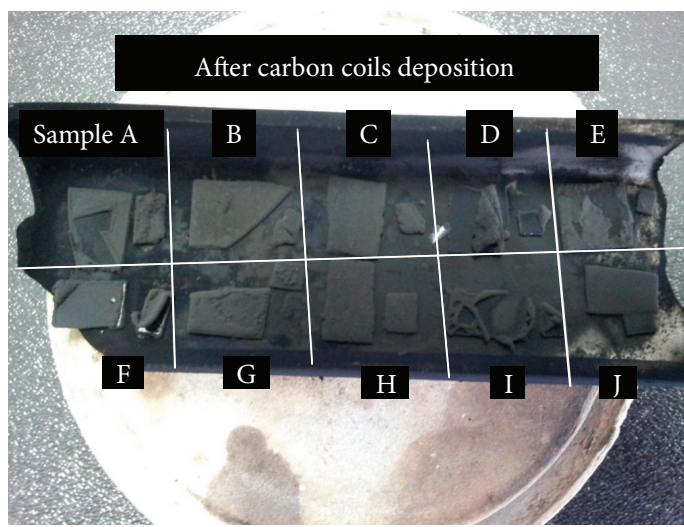

(b)

Figure 1: Photographs of (a) the prepared substrates by the various pretreatment methods and (b) the as-grown carbon coils on these substrates after 10 minutes deposition reaction. Two pieces were shown for each sample. The small piece was used for FESEM investigation.

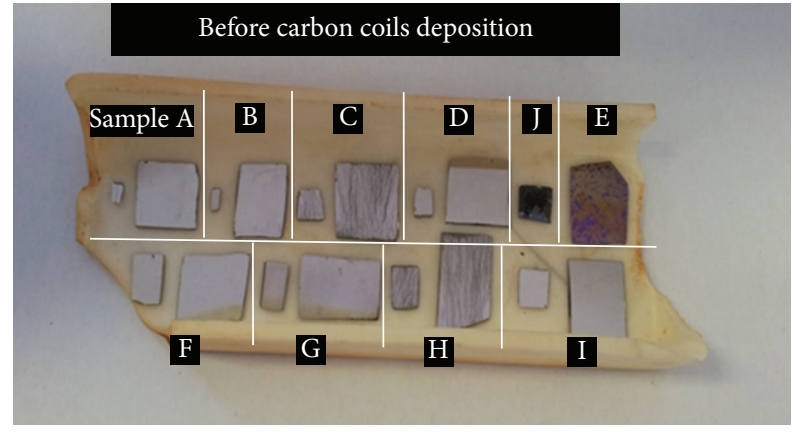

(a)
After carbon coils deposition

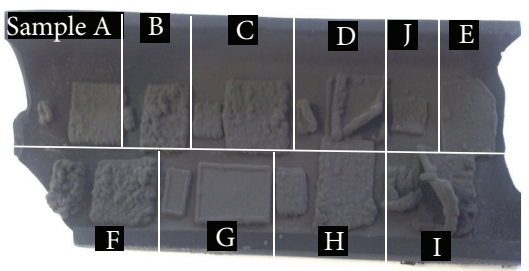

(b)

Figure 2: Photographs of (a) the prepared substrates by the various pretreatment methods and (b) the as-grown carbon coils on these substrates after 60 minutes deposition reaction. Two pieces were shown for each sample. The small piece was used for FESEM investigation.

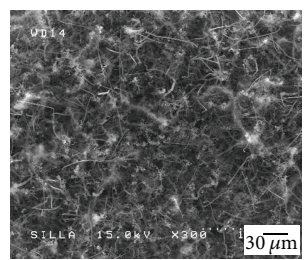

(a)

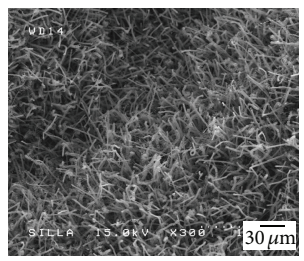

(f)

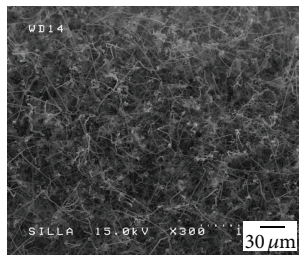

(b)

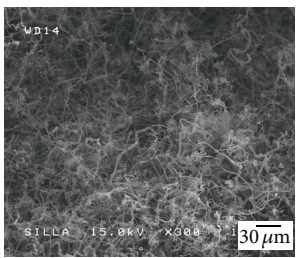

(g)

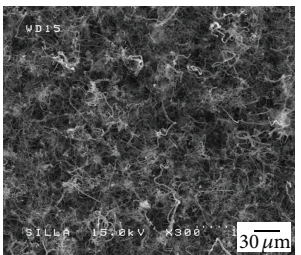

(c)

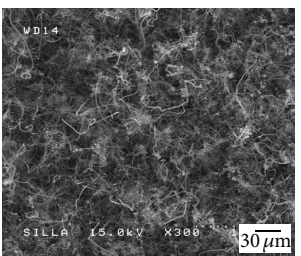

(h)

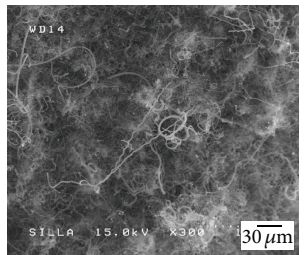

(d)

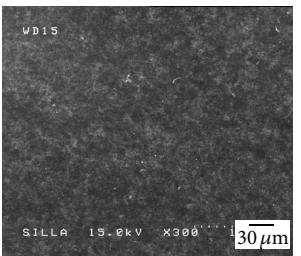

(i)

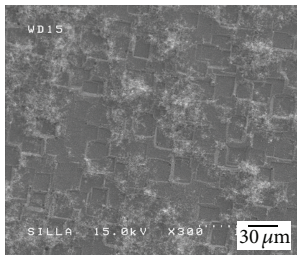

(e)

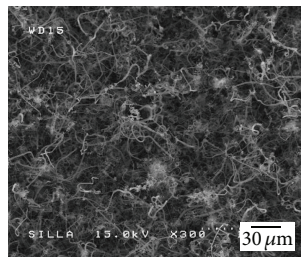

(j)

FIGURE 3: FESEM images for the surface morphologies of the samples after 10 minutes deposition reaction for (a) sample A, (b) sample B, (c) sample C, (d) sample D, (e) sample E, (f) sample F, (g) sample G, (h) sample H, (i) sample I, and (j) sample J. 


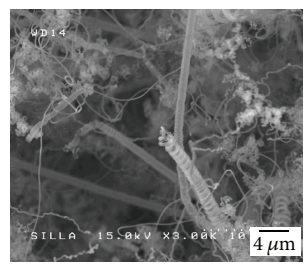

(a)

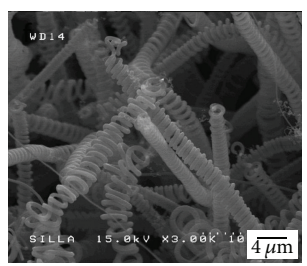

(f)

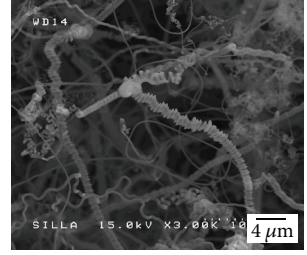

(b)

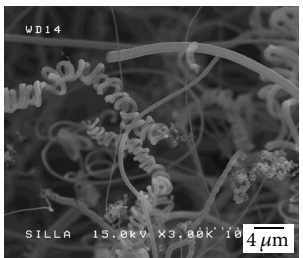

(g)

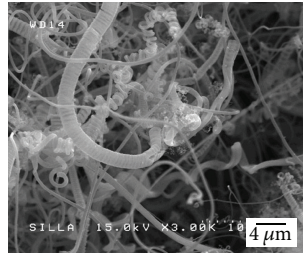

(c)

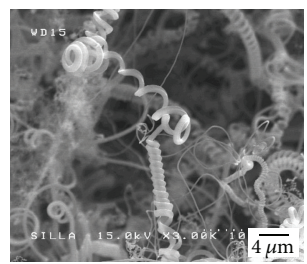

(h)

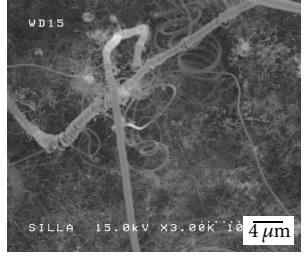

(d)

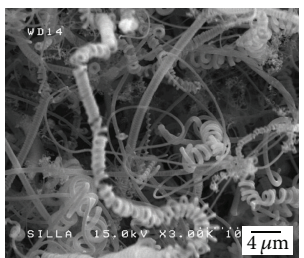

(i)

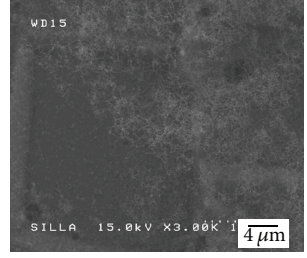

(e)

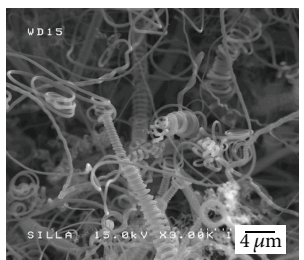

(j)

FIGURE 4: Magnified FESEM images for the surface morphologies of the samples after 10 minutes deposition reaction for (a) sample A, (b) sample B, (c) sample C, (d) sample D, (e) sample E, (f) sample F, (g) sample G, (h) sample H, (i) sample I, and (j) sample J.

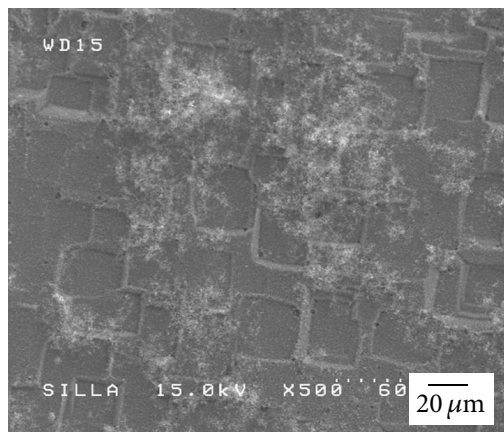

(a)

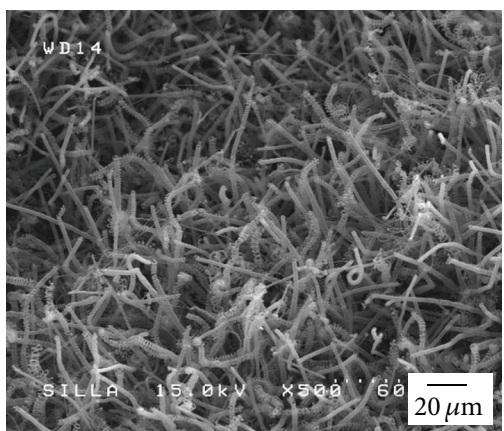

(d)

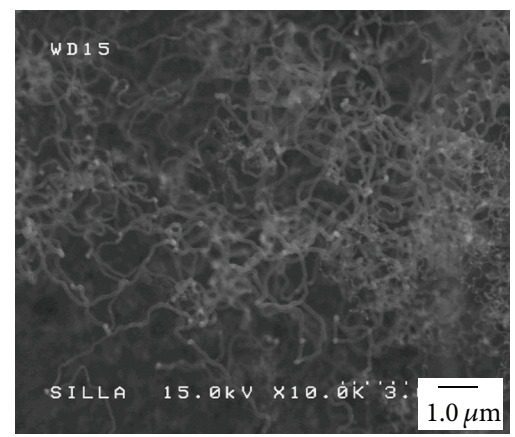

(b)

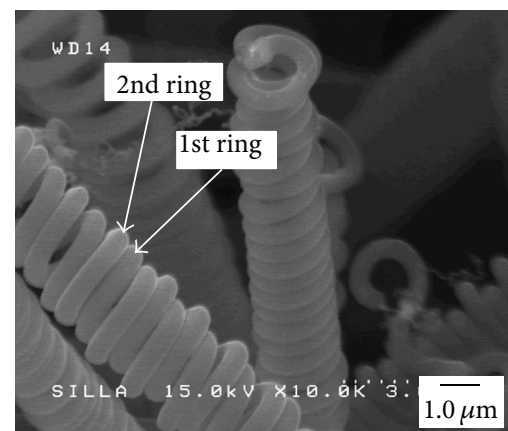

(e)

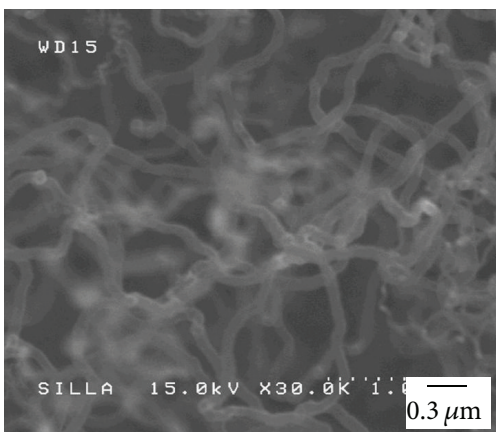

(c)

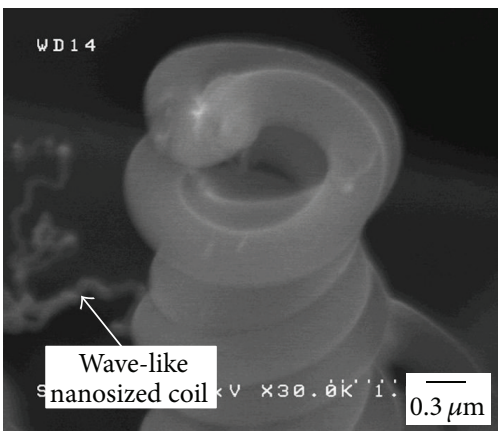

(f)

FIGURE 5: FESEM images for the surface morphologies of the samples after 10 minutes deposition reaction for sample E under the magnification of (a) 500, (b) 10,000, and (c) 30,000 and for sample F under the magnification of (d) 500, (e) 10,000, and (f) 30,000.

of the different ring-type shapes (see the first and second rings in Figure 5(e)). It indicates that the microsized carbon coils formation of this work follows the typical double-helix type geometry. Around the microsized carbon coils, the tiny wave-like nanosized coils were also observed, as shown in Figure 5(f).

After 60 minutes reaction, sample E still reveals the exclusive formation of the nanosized carbon coils, while the other samples show the carbon coils having various geometries (compare Figure 6(e) with the other images in Figure 6). The combined results of Figures 4 and 6 confirm that the exclusive formation of the nanosized carbon coils could be possible by the thermal pretreatment of $\mathrm{Ni}-\mathrm{SiO}_{2}$ substrate with $\mathrm{SF}_{6}$ regardless of the deposition time. For the diamond powders pretreatments on the substrate, meanwhile, only sample $\mathrm{F}$ ( $\mathrm{Si}$ substrate) at the relatively short reaction time (10 minutes) can give the dominant formation of the microsized carbon coils (compare Figures 4(f) with 6(f)). 


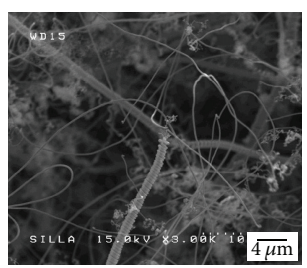

(a)

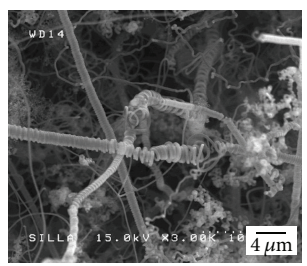

(f)

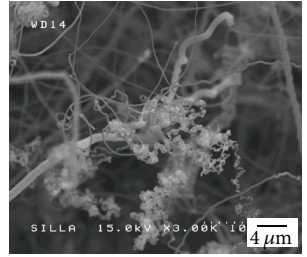

(b)

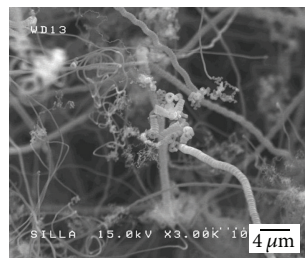

(g)

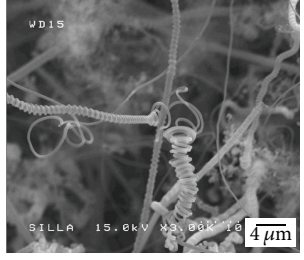

(c)

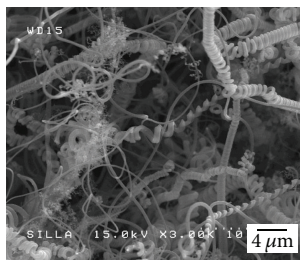

(h)

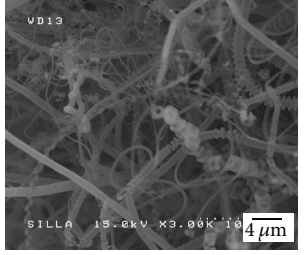

(d)

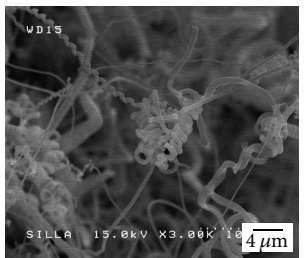

(i)

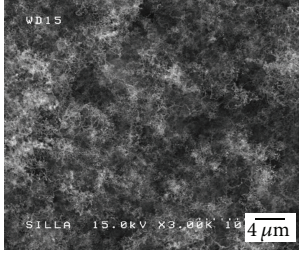

(e)

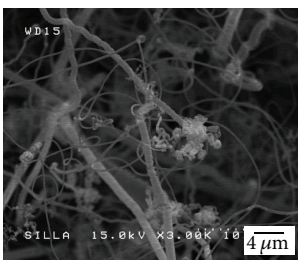

(j)

FIGURE 6: Magnified FESEM images for the surface morphologies of the samples after 60 minutes deposition reaction for (a) sample A, (b) sample B, (c) sample C, (d) sample D, (e) sample E, (f) sample F, (g) sample G, (h) sample H, (i) sample I, and (j) sample J.

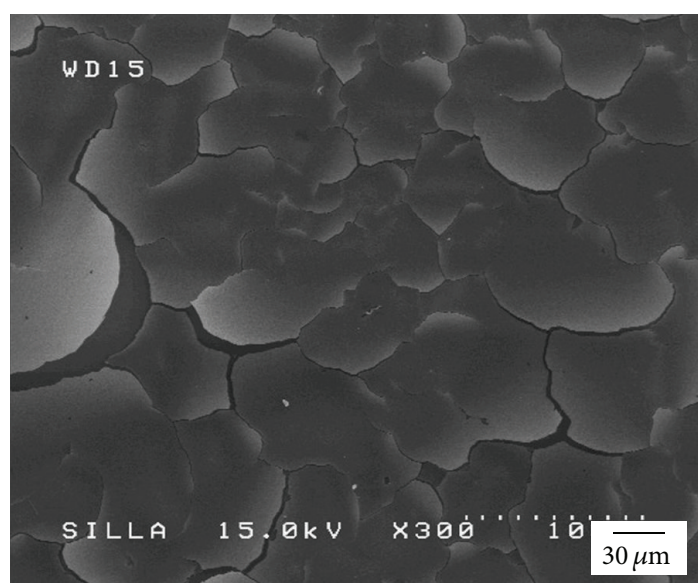

FIGURE 7: FESEM images indicating the situation of the peeled-off $\mathrm{Ni}$ layers from $\mathrm{Ni}-\mathrm{SiO}_{2}$ substrate by the thermal pretreatment with $\mathrm{SF}_{6}$ after cooling down this substrate from $750^{\circ} \mathrm{C}$ to $25^{\circ} \mathrm{C}$ under vacuum condition.

For $\mathrm{SiO}_{2}$ substrate, the thermal pretreatment with $\mathrm{SF}_{6}$ seems to increase the stress between the predeposited $\mathrm{Ni}$ catalyst layer and $\mathrm{SiO}_{2}$ substrate. Figure 7 shows FESEM images indicating the situation of the peeled-off $\mathrm{Ni}$ layers from the substrate with the thermal pretreatment (sample E) after cooling down the substrate from $750^{\circ} \mathrm{C}$ to $25^{\circ} \mathrm{C}$ under vacuum condition. As shown in this image, $\mathrm{SiO}_{2}$ substrate with the thermal pretreatment gives rise to the flaky state for Ni layer, which may form the nanosized Ni pieces during the reaction. Basically, the mechanism of the carbon coils growth was dependent on the metal size and shape [19]. The nanosized carbon coils were formed from the nanosized $\mathrm{Ni}$ pieces, and then they would deposit on the whole surface of the substrate. This seems to be the reason why the thermal pretreatment with $\mathrm{SF}_{6}$ gives rise to the exclusive formation of the nanosized carbon coils on the entire surface of $\mathrm{SiO}_{2}$ substrate. For Si substrate, the combined results of samples

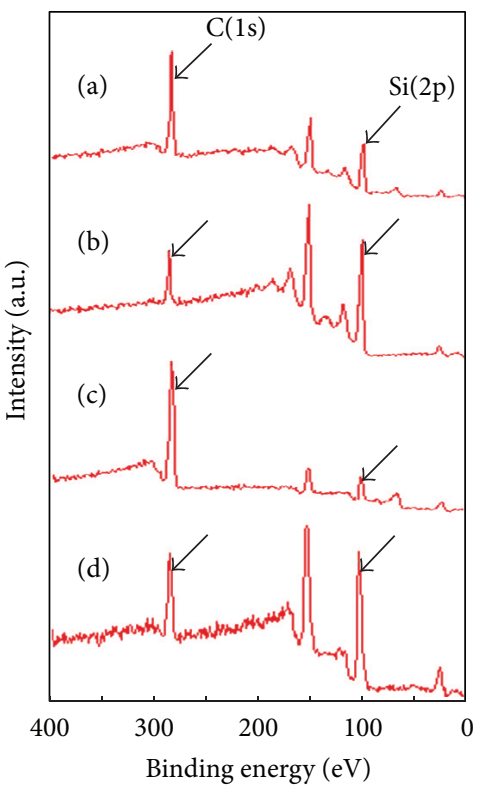

FIGURE 8: XPS spectra of the substrate surface before the carbon coils deposition reaction for (a) sample A, (b) sample C, (c) sample $\mathrm{F}$, and (d) sample $\mathrm{H}$.

$\mathrm{E}$ and $\mathrm{J}$ confirm that the thermal pretreatment with $\mathrm{SF}_{6}$ on $\mathrm{Ni}-\mathrm{Si}$ substrate, compared with that on $\mathrm{Ni}-\mathrm{SiO}_{2}$ substrate, shows various geometries for as-grown carbon coils (compare Figures 3(e) with 3(j)). The different thermal expansion coefficient value $[20,21]$ between the predeposited Ni catalyst layer and the different substrates $\left(\mathrm{SiO}_{2}\right.$ or $\mathrm{Si}$ substrate) seems to be the main reason for these different results [22].

Figure 8 shows XPS spectra for samples A, C, F, and H, indicating the existence of the carbon component on the surface of the $\mathrm{Si}$ or $\mathrm{SiO}_{2}$ substrate by the pretreatment method-A or -B. $I_{\mathrm{c}(1 \mathrm{~s})} / I_{\mathrm{si}(2 \mathrm{p})}$ for samples A, C, F, and $\mathrm{H}$ were measured to be about $1.49,0.35,5.20$, and 0.53 , respectively. These 
results show that the amount of the remained carbon species is largest in the case of $\mathrm{Si}$ substrate and the pretreatment method-A combination (sample F) than any other case. It clearly confirms that the diamond powder pretreatment on Si substrate would leave the carbon particles on the surface of the substrate [23]. Therefore, these remained carbon particles seem to effectively motivate the formation of the microsized carbon coils during the relatively short reaction time (10 minutes). At the relatively longer reaction time (90 minutes in this work), on the other hand, the influence of the substrateremained carbon particles on the geometry formation for asgrown carbon coils seems to be diminished. At this point, therefore, the existence of the remained carbon particles by the diamond powders pretreatment is considered to be the main cause for the dominant formation of the microsized carbon coils on $\mathrm{Si}$ substrate during the relatively short reaction time (10 minutes).

\section{Conclusion}

Diamond powders pretreatment of Si substrate left the carbon particles on the substrate surface. The remained carbon particles are considered to be the main cause for the formation of the dominant formation of the microsized carbon coils after the relatively short reaction time (10 minutes). Thermal etching pretreatment of $\mathrm{Ni}-\mathrm{SiO}_{2}$ substrate with $\mathrm{SF}_{6}$ exclusively produces the nanosized carbon coils. The great difference of the thermal expansion coefficient value between the predeposited $\mathrm{Ni}$ catalyst layer and $\mathrm{SiO}_{2}$ substrate seems to develop the nanosized $\mathrm{Ni}$ pieces during the carbon coils deposition reaction. Eventually, it produces the exclusive formation of the nanosized carbon coils on the entire surface of $\mathrm{SiO}_{2}$ substrate.

\section{Acknowledgment}

This research was supported by Basic Science Research Program through the National Research Foundation of Korea (NRF) funded by the Ministry of Education, Science, and Technology (2013R1A1A2007157).

\section{References}

[1] S. Amelinckx, X. B. Zhang, D. Bernaerts, X. F. Zhang, V. Ivanov, and J. B. Nagy, "A formation mechanism for catalytically grown helix-shaped graphite nanotubes," Science, vol. 265, no. 5172, pp. 635-637, 1994.

[2] A. Fonseca, K. Hernadi, J. B. Nagy, P. Lambin, and A. A. Lucas, "Model structure of perfectly graphitizable coiled carbon nanotubes," Carbon, vol. 33, no. 12, pp. 1759-1775, 1995.

[3] O.-Y. Zhong-Can, Z.-B. Su, and C.-L. Wang, "Coil formation in multishell carbon nanotubes: competition between curvature elasticity and interlayer adhesion," Physical Review Letters, vol. 78, no. 21, pp. 4055-4058, 1997.

[4] V. Bajpai, L. Dai, and T. Ohashi, "Large-scale synthesis of perpendicularly aligned helical carbon nanotubes," Journal of the American Chemical Society, vol. 126, no. 16, pp. 5070-5071, 2004.
[5] X. Wang, Z. Hu, Q. Wu, X. Chen, and Y. Chen, "Synthesis of multi-walled carbon nanotubes by microwave plasmaenhanced chemical vapor deposition," Thin Solid Films, vol. 390, no. 1-2, pp. 130-133, 2001.

[6] A. Huczko, "Synthesis of aligned carbon nanotubes," Applied Physics A, vol. 74, no. 5, pp. 617-638, 2002.

[7] N. M. Rodriguez, "A review of catalytically grown carbon nanofibers," Journal of Materials Research, vol. 8, no. 12, pp. 3233-3250, 1993.

[8] M. Kawaguchi, K. Nozaki, S. Motojima, and H. Iwanaga, "A growth mechanism of regularly coiled carbon fibers through acetylene pyrolysis," Journal of Crystal Growth, vol. 118, no. 34, pp. 309-313, 1992.

[9] Q. Zhang, L. Yu, and Z. Cui, "Effects of the size of nanocopper catalysts and reaction temperature on the morphology of carbon fibers," Materials Research Bulletin, vol. 43, no. 3, pp. 735-742, 2008.

[10] S. Hokushin, L. Pan, and Y. Nakayama, "Diameter control of carbon nanocoils by the catalyst of organic metals," Japanese Journal of Applied Physics, Part 1, vol. 46, no. 8, pp. 5383-5385, 2007.

[11] N. Tang, J. Wen, Y. Zhang, F. Liu, K. Lin, and Y. Du, "Helical carbon nanotubes: catalytic particle size-dependent growth and magnetic properties," ACS Nano, vol. 4, no. 1, pp. 241-250, 2010.

[12] J. B. Nagy, G. Bister, A. Fonseca et al., "On the growth mechanism of single-walled carbon nanotubes by catalytic carbon vapor deposition on supported metal catalysts," Journal of Nanoscience and Nanotechnology, vol. 4, no. 4, pp. 326-345, 2004.

[13] Z. Yu, D. Chen, B. Tøtdal, and A. Holmen, "Effect of support and reactant on the yield and structure of carbon growth by chemical vapor deposition," Journal of Physical Chemistry B, vol. 109, no. 13, pp. 6096-6102, 2005.

[14] C. Park and M. A. Keane, "Catalyst support effects in the growth of structured carbon from the decomposition of ethylene over nickel," Journal of Catalysis, vol. 221, no. 2, pp. 386-399, 2004.

[15] Z. Y. Huang, X. Chen, J. R. Huang, M. Q. Li, and J. H. Liu, "Synthesis of carbon nanocoils on surface morphology changed silicon substrates," Materials Letters, vol. 60, no. 17-18, pp. 20732075, 2006.

[16] M. Ch. Veziri, G. N. Karanikolos, G. Pilatos et al., "Growth and morphology manipulation of carbon nanostructures on porous supports," Carbon, vol. 447, no. 9, pp. 2161-2173, 2009.

[17] J. B. Bai, "Growth of nanotube/nanofibre coils by CVD on an alumina substrate," Materials Letters, vol. 57, no. 18, pp. 26292633, 2003.

[18] J. H. Eum, S. H. Kim, S. S. Yi, and K. Jang, "Large-scale synthesis of the controlled- geometry carbon coils by the manipulation of the SF6 gas flow injection time," Journal of Nanoscience and Nanotechnology, vol. 12, no. 5, pp. 4397-4402, 2012.

[19] N. M. Rodriguez, "A review of catalytically grown carbon nanofibers," Journal of Materials Research, vol. 8, no. 12, pp. 3233-3250, 1993.

[20] H. Tada, A. E. Kumpel, R. E. Lathrop et al., "Thermal expansion coefficient of polycrystalline silicon and silicon dioxide thin films at high temperatures," Journal of Applied Physics, vol. 87, no. 9, pp. 4189-4193, 2000.

[21] T. G. Kollie, "Measurement of the thermal-expansion coefficient of nickel from 300 to $1000 \mathrm{~K}$ and determination of the powerlaw constants near the Curie temperature," Physical Review B, vol. 16, no. 11, pp. 4872-4881, 1977. 
[22] S. Park, S. H. Kim, and T.-G. Kim, "Effect of Si and $\mathrm{SiO}_{2}$ substrates on the geometries of as-grown carbon coils," Journal of Nanomaterials, vol. 2012, Article ID 389248, 8 pages, 2012.

[23] S. H. Kim, Y. S. Park, S. K. Jung, D. H. Kang, and J.-W. Lee, "Effect of the substrate state on the formation of diamond film in a low temperature microwave-plasma-enhanced chemical vapor deposition system," Journal of Vacuum Science \& Technology A, vol. 13, no. 3, pp. 1619-1623, 1995. 

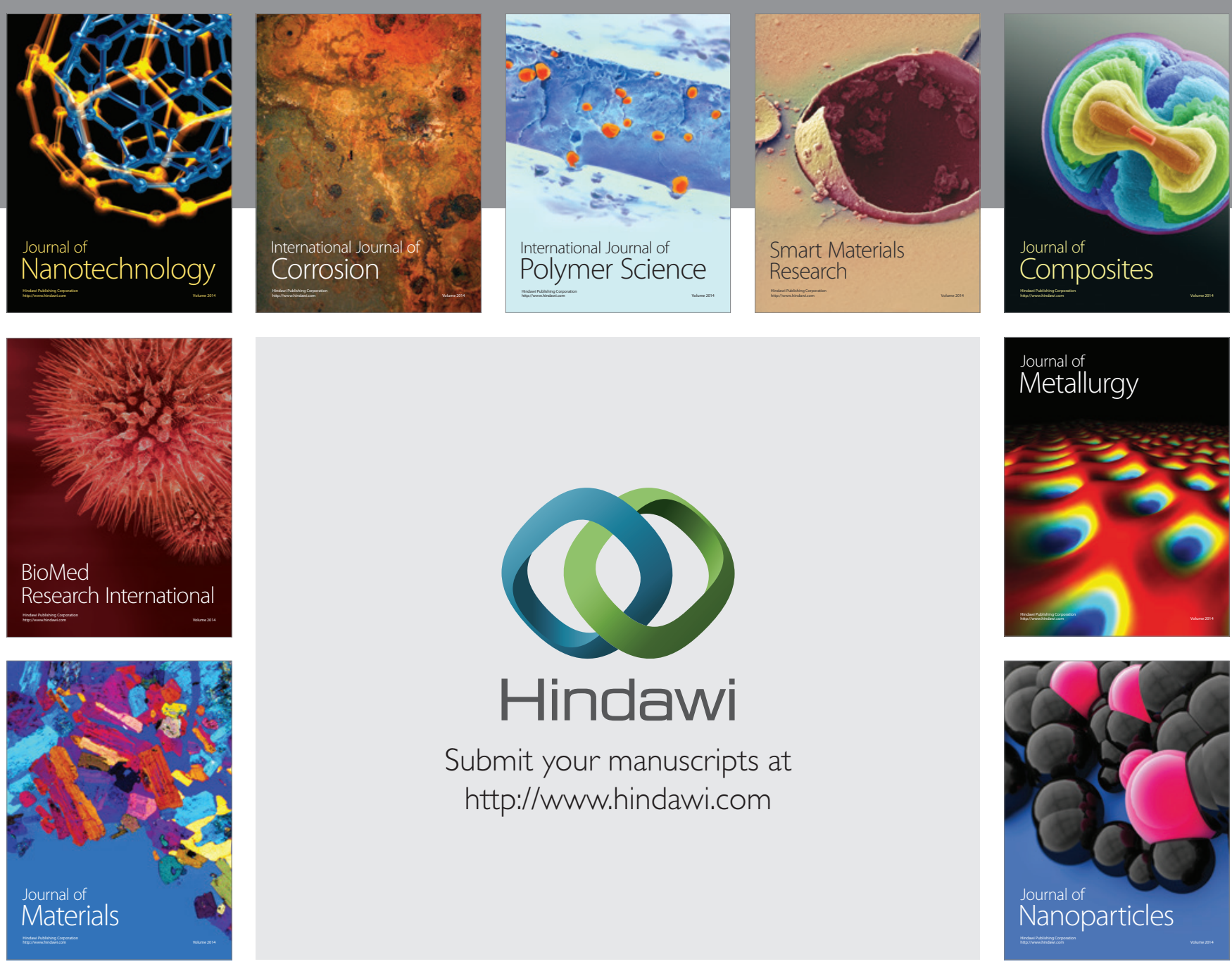

Submit your manuscripts at http://www.hindawi.com
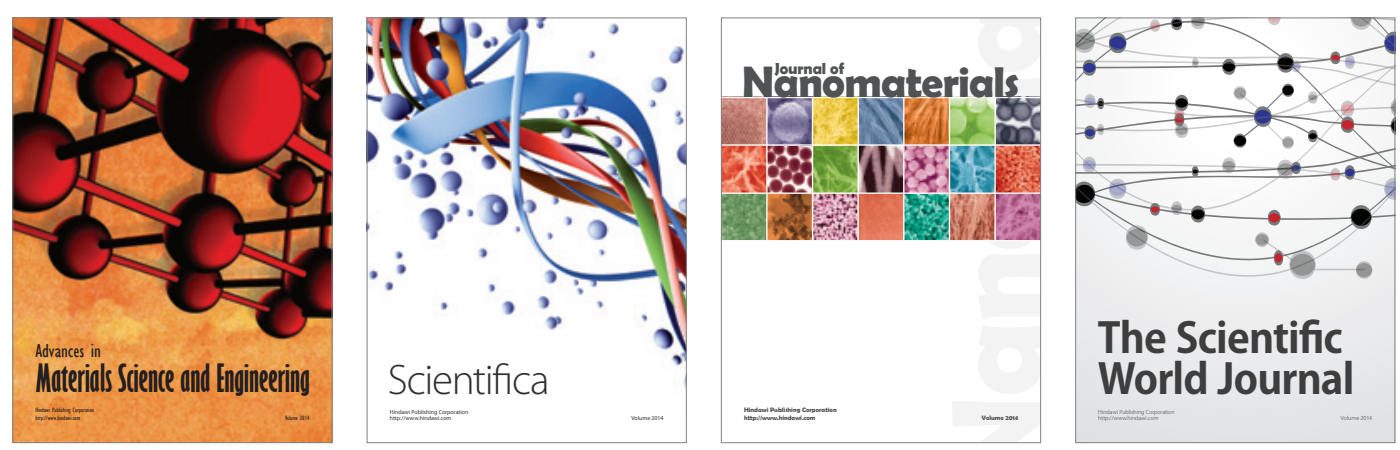

\section{The Scientific World Journal}
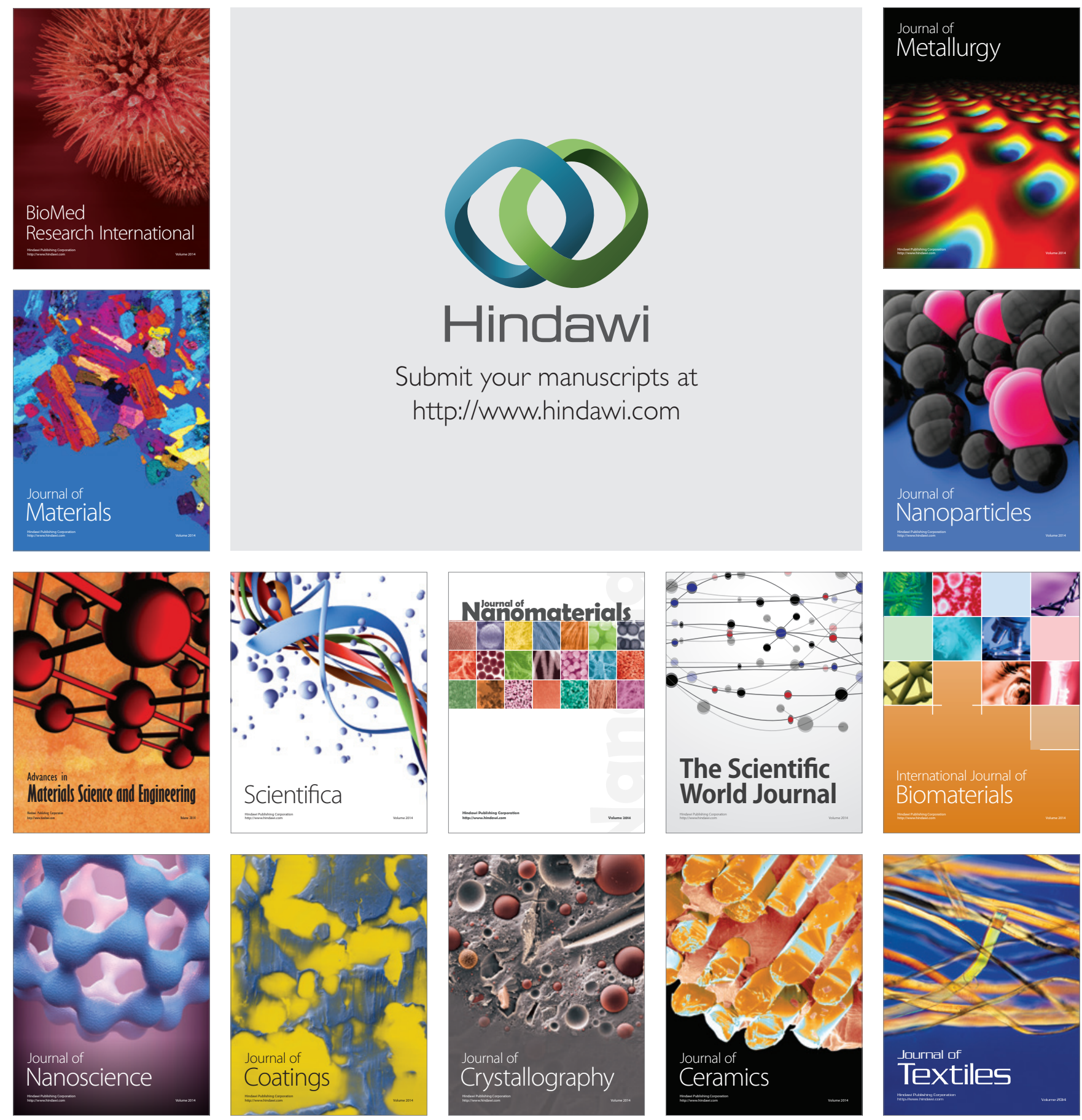